\title{
Affinity informs environmental cooperation between ammonia- oxidizing archaea (AOA) and anaerobic ammonia-oxidizing (Anammox) bacteria
}

\author{
Levi L. Straka $\mathbb{1}^{1} \cdot$ Kelley A. Meinhardt ${ }^{1} \cdot$ Annette Bollmann $^{2} \cdot$ David A. Stahl $^{1} \cdot$ Mari-K. H. Winkler $^{1}$
}

Received: 14 December 2018 / Revised: 18 February 2019 / Accepted: 15 March 2019 / Published online: 1 April 2019

(c) International Society for Microbial Ecology 2019

\begin{abstract}
Anaerobic ammonia-oxidizing (Anammox) bacteria (AnAOB) rely on nitrite supplied by ammonia-oxidizing bacteria (AOB) and archaea (AOA). Affinities for ammonia and oxygen play a crucial role in AOA/AOB competition and their association with AnAOB. In this work we measured the affinity constants for ammonia and oxygen (half-saturation; $k_{\mathrm{m}}$ ) of two freshwater AOA enrichments, an AOA soil isolate ( $N$. viennensis), and a freshwater AnAOB enrichment. The AOA enrichments had similar kinetics $\left(\mu_{\max } \approx 0.36 \mathrm{~d}^{-1}, k_{\mathrm{m}, \mathrm{NH} 4} \approx 0.78 \mu \mathrm{M}\right.$, and $\left.k_{\mathrm{m}, \mathrm{O} 2} \approx 2.9 \mu \mathrm{M}\right)$, whereas $N$. viennensis had similar $k_{\mathrm{m}}$ values but lower $\mu_{\max }\left(0.23 \mathrm{~d}^{-1}\right)$. In agreement with the current paradigm, these AOA strains showed a higher affinity for ammonia (lower $\left.k_{\mathrm{m}, \mathrm{NH} 4} ; 0.34-1.27 \mu \mathrm{M}\right)$ than published AOB measurements $(>20 \mu \mathrm{M})$. The slower growing AnAOB $\left(\mu_{\max } \approx\right.$ $\left.0.16 \mathrm{~d}^{-1}\right)$ had much higher $\mathrm{k}_{\mathrm{m}}$ values $\left(k_{\mathrm{m}, \mathrm{NH} 4} \approx 132 \mu \mathrm{M}, k_{\mathrm{m}, \mathrm{NO} 2} \approx 48 \mu \mathrm{M}\right)$ and were inhibited by oxygen at low levels (halfoxygen inhibition; $k_{\mathrm{i}, \mathrm{O} 2} \approx 0.092 \mu \mathrm{M}$ ). The higher affinity of AOA for ammonia relative to AnAOB, suggests AOA/AnAOB cooperation is only possible where AOA do not outcompete AnAOB for ammonia. Using a biofilm model, we show that environments of ammonia/oxygen counter diffusion, such as stratified lakes, favors this cooperation.
\end{abstract}

\section{Introduction}

Anaerobic ammonia oxidizing (Anammox) bacteria (AnAOB) grow autotrophically on ammonia and nitrite under oxygen deplete conditions, which gives them a unique ecological niche. As a result, AnAOB are widely distributed in suboxic environments throughout the world, including marine, freshwater, terrestrial, and various extreme environments $[1,2]$. In fact, it is estimated that Anammox is responsible for $\sim 30 \%$ of global oceanic nitrogen loss [3]. However, the use of nitrite necessitates

Supplementary information The online version of this article (https:// doi.org/10.1038/s41396-019-0408-x) contains supplementary material, which is available to authorized users.

$\triangle$ Levi L. Straka

lstraka@asu.edu

1 Department of Civil and Environmental Engineering, University of Washington, 201 More Hall, Box 352700, Seattle, WA 981952700, USA

2 Miami University, Department of Microbiology, 212 Pearson Hall, 700 E. High St., Oxford, OH 45056, USA synergistic relationships between AnAOB and organisms that produce it, including ammonia oxidizing bacteria (AOB) and archaea (AOA) that aerobically oxidize ammonia to nitrite [4]. Since Anammox is inhibited by oxygen there is a delicate oxygen balance between the aerobic and anaerobic oxidation of ammonia. For example, in the oxic/anoxic boundary region of the stratified water column of the Black Sea, diffusion of nitrite produced by microaerophilic AOA and AOB growing in the upper lowoxygen region supports $A n A O B$ in the adjacent lower suboxic region $(<5 \mu \mathrm{M}$ oxygen) [5]. Another example of their concomitant growth is in engineered biofilm systems, such as granular sludge wastewater treatment, where AOB reside in the aerobic surface layer of the spherical biofilm and $\mathrm{AnAOB}$ reside in an anoxic interior [6].

$\mathrm{AOB}$ are the dominant ammonia oxidizers in most wastewater treatment plants due to their copiotrophic growth characteristics [7,8], whereas AOA dominate oligotrophic open oceans and soils where ammonia concentrations are significantly lower $[9,10]$. AOB and AOA affinity, or the degree that these organisms can grow at low levels of ammonia and oxygen, therefore plays a crucial role in niche differentiation [11]. AOA also have a more efficient pathway for carbon fixation than do the AOB, 
contributing to better growth on limited substrate [12] Similarly, affinity plays a role in niche differentiation of AnAOB species, where it has been suggested that members of the Brocadia clade are copiotrophic and dominate under nutrient replete conditions whereas members of the Kuenenia clade have more oligotrophic characteristics [1, 13]. Finally, affinity plays a role in cooperation (passing of nitrite) and competition (for ammonia) between AOA or $\mathrm{AOB}$ and AnAOB.

Since affinity plays a large role in determining what environments $\mathrm{AnAOB}$ and $\mathrm{AOA}$ or $\mathrm{AOB}$ cooperate and compete, in this work we characterized the kinetic affinity constants (half-saturation concentrations; $k_{\mathrm{s}}$ ) of two freshwater AOA enrichment cultures, one AOA pure culture $(N$. viennensis), and an $\mathrm{AnAOB}$ enrichment. Those data were then used to model environments supporting the synergistic association of ecotypes having differing affinities. Those analyses suggest that $\mathrm{AOA}$ and $\mathrm{AnAOB}$ cooperation is enhanced by cross-diffusional conditions (as in the ocean), whereas $\mathrm{AOB}$ and $\mathrm{AnAOB}$ cooperative growth is more compatible with co-diffusional habitats (as in biofilm systems).

\section{Materials and methods}

\section{$A O A$ and $A n A O B$ culturing}

Three AOA strains were used in this study, enrichments from Lakes Delaware (DW) and Acton (AC2) in Ohio, and a pure culture Nitrososphaera viennensis isolated from soil, all belonging to the group I.1a of the Thaumarchaeota [14, 15]. On the basis of ammonia monooxygenase gene sequence comparisons, $\mathrm{AC} 2$ is $82 \%$ identical to DW, and $N$. viennensis is 70 and $71 \%$ identical to $\mathrm{AC} 2$ and $\mathrm{DW}$, respectively [15]. AnAOB granular biomass collected from an Anammox reactor treating anaerobic digester effluent pretreated with a nitritation reactor was provided by the wastewater treatment plant in Rotterdam Sluisjesdijk, the Netherlands [16]. The dominant Anammox organism in this sludge was Brocadia anammoxidans [16]. All cultures were grown at $30^{\circ} \mathrm{C}$ in Crenarchaeota Medium containing $1 \mathrm{mM}$ or $2 \mathrm{mM} \mathrm{NH}_{4} \mathrm{Cl}$. Per L the media contained: 53.5 or $107 \mathrm{mg}$ $\mathrm{NH}_{4} \mathrm{Cl}$, $476.8 \mathrm{mg}$ HEPES, $48 \mathrm{mg} \mathrm{NaOH}, 585 \mathrm{mg} \mathrm{NaCl}, 75$ $\mathrm{mg} \mathrm{KCl}, 147 \mathrm{mg} \mathrm{CaCl}{ }_{2} \cdot 2 \mathrm{H}_{2} \mathrm{O}$, and $49 \mathrm{mg} \mathrm{MgSO}_{4} \cdot 7 \mathrm{H}_{2} \mathrm{O}$, $168 \mathrm{mg} \mathrm{NaCO}$, $2.8 \mathrm{mg}$ FeNaEDTA, $0.2 \mathrm{mg} \mathrm{KH}_{2} \mathrm{PO}_{4}$, and $1 \mathrm{ml}$ trace minerals mixture (per L): $8 \mathrm{~mL} 37 \% \mathrm{HCl}, 30 \mathrm{mg}$ $\mathrm{H}_{3} \mathrm{BO}_{3}, 100 \mathrm{mg} \mathrm{MnCl}_{2} \cdot 4 \mathrm{H}_{2} \mathrm{O}, 190 \mathrm{mg} \mathrm{CoCl} \cdot 6 \mathrm{H}_{2} \mathrm{O}, 24 \mathrm{mg}$ $\mathrm{NiCl}_{2} \cdot 6 \mathrm{H}_{2} \mathrm{O}, 2 \mathrm{mg} \mathrm{CuCl} 2 \cdot 2 \mathrm{H}_{2} \mathrm{O}, 144 \mathrm{mg} \mathrm{ZnSO}{ }_{4} \cdot 7 \mathrm{H}_{2} \mathrm{O}$, and $36 \mathrm{mg} \mathrm{Na} 2 \mathrm{MoO}_{4} \cdot 2 \mathrm{H}_{2} \mathrm{O}$. Sustained growth of $N$. viennensis required the addition of $1 \mathrm{mM}$ pyruvate as previously reported [14]. AnAOB cultures were supplemented with 1.3 or $2.0 \mathrm{mM} \mathrm{NaNO}$. Except during AOA batch growth tests, nitrite, ammonia (total ammonia; ammonia and ammonium), and total oxidized nitrogen (TON; nitrite plus nitrate) were measured using a Gallery ${ }^{\mathrm{TM}}$ Automated Photometric Analyzer (ThermoFisher Scientific, Waltham, MA U.S.A.) with the respective reagents, and measurements were calibrated using $\mathrm{NaNO}_{2}, \mathrm{NH}_{4} \mathrm{Cl}$, and $\mathrm{NaNO}_{3}$, respectively. During batch growth tests, nitrite was measured by hand colorimetrically using diazotized sulfanilamide and NED dihydrochloride [17].

\section{Maximum specific growth rate for AOA}

The maximum specific growth rate $\left(\mu_{\max }\right)$ of the four strains as well as the kinetics for oxygen (limitation of AOA or inhibition of AnAOB), ammonia limitation, and nitrite limitation of AnAOB were characterized for all cultures. For determination of the $\mu_{\max }$ of AOA, cultures were placed in $100 \mathrm{ml}$ of media in an unmixed closed $250 \mathrm{ml}$ glass media bottle. AOA activity was tracked by measuring nitrite production, which is presumed proportional to biomass production, and $\mu_{\max }$ was fit to the resultant exponential growth curve. These tests were conducted at both $1 \mathrm{mM}$ and $2 \mathrm{mM} \mathrm{NH}_{4} \mathrm{Cl}$.

\section{Oxygen and ammonia affinities for AOA}

Similar to studies reported by Martens-Habbena et al. [11], AOA nutrient limitation tests were conducted using a Unisense oxygen needle sensor OX-N 13621 (Unisense, Aarhus N, Denmark) to measure activity. $120 \mathrm{ml}$ of culture was placed in a $120 \mathrm{ml}$ serum bottle (no head space), sealed with a rubber stopper, and continuously mixed using a magnetic stir bar to ensure homogeneity. The oxygen sensor was calibrated using a two-point calibration with the zero taken as the flat line of the oxygen depletion experiments and a saturation point $\left(0.238 \mathrm{mM}\right.$ at $\left.30^{\circ} \mathrm{C}\right)$ taken by bubbling air in deionized water for at least an hour. The sensor was inserted through a hole punched through the rubber stopper and calked around it to prevent gas exchange. Oxygen measurements were taken every minute and "smoothed" by taking a 30 min average, computing oxygen consumption as the change in oxygen divided by the time step (1 min). Oxygen affinity was determined by tracking oxygen consumption as oxygen was depleted, and ammonia affinity was determined by tracking oxygen consumption as ammonia was depleted.

All AOA nutrient limitation results followed MichaelisMenten type kinetics:

$\mu=\frac{\mu_{\max } S}{S+k_{m}}$

where $\mu$ is the specific growth rate $\left(\mathrm{mM} \mathrm{O}_{2} \mathrm{~d}^{-1} \mathrm{mM}\right.$ $\mathrm{NO}_{2}{ }^{-1}$ ), $S$ is the limiting substrate concentration (oxygen or 
ammonia; $\mathrm{mM}$ ), and $k_{\mathrm{m}}$ is the half-saturation constant (mM). We determined $\mu$ by taking the oxygen consumption $\left(\mathrm{mM} \mathrm{O} \mathrm{O}_{2} \mathrm{~d}^{-1}\right)$ normalized to nitrite concentration $(\mathrm{mM}$ $\mathrm{NO}_{2}$ ), which was assumed to be proportional to biomass production. The unit conversion between $\mathrm{d}^{-1}$ (reported for the exponential growth $\mu_{\max }$ determination) and $\mathrm{mM} \mathrm{O}_{2} \mathrm{~d}^{-1}$ $\mathrm{mM} \mathrm{NO}_{2}{ }^{-1}$ (reported $\mu$ for the nutrient limitation experiments) was assumed 1.5 (i.e., nitrite is produced in a 1:1.5 ratio of nitrite produced to oxygen consumed). To determine $k_{\mathrm{m}}, \mu$ was plotted against oxygen or ammonia depending on which nutrient was depleted in that experiment to generate an affinity curve. For ammonia, the ammonia concentration was computed by assuming ammonia is consumed at a 1.5:1 ratio to oxygen and was depleted when oxygen consumption stopped. The $\mu_{\max }$ value was fixed to the average value determined for each organism, and the initial biomass concentration (as nitrite) and $k_{\mathrm{m}}$ were fit by minimizing the sum of squared difference between the measured and modeled $\mu$ using Microsoft ${ }^{\circledR}$ Excel 2016 and the Solver Add-in. Initial nitrite concentration (surrogate for biomass) was fit instead of using an initial measurement because unlike during $\mu_{\max }$ determination, the biomass had gone through periods of starvation, and, therefore, biomass had decayed when nitrite had not, and measured nitrite was not a reliable measure of initial biomass concentration.

\section{Maximum specific growth rate for AnAOB}

Similar to AOA, AnAOB $\mu_{\max }$ was determined by growing the AnAOB enrichment in a batch culture and measuring the removal of ammonia and nitrite. AnAOB granules were broken up using a tissue potter and grown in serum bottle batch cultures. Bottles were sparged with nitrogen gas to remove oxygen prior to initiating batch growth and mixed with a stir bar throughout the experiment. The $\mu_{\max }$ was determined by fitting to the exponential nitrite removal curve (taken as the nitrite measurement at each time point minus the initial nitrite). Thus, each batch culture yielded two $\mu_{\max }$ values (from ammonia and nitrite). However, $\mu_{\max }$ determined using ammonia was systematically higher than for nitrite. We speculated that there were other organisms in the AnAOB culture contributing to this consumption (e.g., due to ammonia assimilation) as indicated by the reported ratio of nitrite to ammonia consumed during these tests. Since ammonia $\mu_{\max }$ was not a reliable measure of Anammox activity, $\mu_{\max }$ was only determined using nitrite removal.

\section{Oxygen and ammonia affinities for AnAOB}

Nutrient limitation and oxygen inhibition were determined using septum bottles with OxiTop anaerobic pressure sensing heads (Xylem Analytics Germany Sales GmbH \& Co. KG, Oberbayern, Germany), which detects pressure difference caused by the dinitrogen gas produced during anaerobic ammonia oxidation. The OxiTop system recorded a pressure every 1-4 min depending on the duration of the experiment recorded (6-24h). Because the OxiTop system reports the pressure in discrete increments of whole number $\mathrm{hPa}$, the pressure data was "smoothed" by taking a $2 \mathrm{~h}$ average, as opposed to the $30 \mathrm{~min}$ average used with the oxygen sensor. Gas production was computed as the change in pressure divided by the time step between sampling points. Ammonia and nitrite were measured at the beginning and end of each OxiTop experiment. Comparing the change in pressure to the change in ammonia or nitrite gave an approximate ratio of ammonia or nitrite consumed to gas pressure produced, which was used to compute a curve of continuous nitrite and ammonia consumption at the resolution of the pressure readings. The nitrite consumption rate was used as the measured $\mu$, which, along with the nitrite or ammonia concentrations, were used to determine $k_{\mathrm{m}}$. Similar to the procedure for AOA, the $\mu_{\max }$ value was fixed to the average value determined in the exponential growth experiment, and the initial biomass concentration (as nitrite) and $k_{\mathrm{m}}$ were fit by minimizing the sum of squared difference between the measured and modeled $\mu$ using Excel Solver.

\section{Oxygen inhibition for AnAOB}

For oxygen inhibition of Anammox, the OxiTop system was again used to measure activity. In addition, a Unisense oxygen needle sensor OX-N 13621 (same as was used for the AOA nutrient limitation tests) was inserted into the OxiTop serum bottle to track oxygen. At the beginning of the experiment a small volume of pure oxygen was injected into the bottle $\left(0.8-1.2 \mu \mathrm{M} \mathrm{O}_{2}\right.$ as measured by the oxygen sensor). The microbial community in the AnAOB enrichment slowly consumed the oxygen until it was depleted. The resulting pressure reading showed a slow decline in pressure as the oxygen was consumed and began to increase once Anammox activity was resumed (presented in Supplemental Information Figure S13). Similar to the $k_{\mathrm{m}}$ values, the half-maximum inhibition concentration of oxygen $\left(k_{\mathrm{i}} ; \mathrm{mM}\right)$ was determined using $\mu$ (computed from pressure change) and oxygen concentration, and $k_{\mathrm{i}}$ and initial biomass concentration (as nitrite) were fit using Excel Solver.

A typical inhibition function was used to describe oxygen inhibition:

$\mu=\frac{\mu_{\max } * k_{i}}{k_{i}+S}$

where $S$ is the oxygen concentration $(\mathrm{mM})$. 


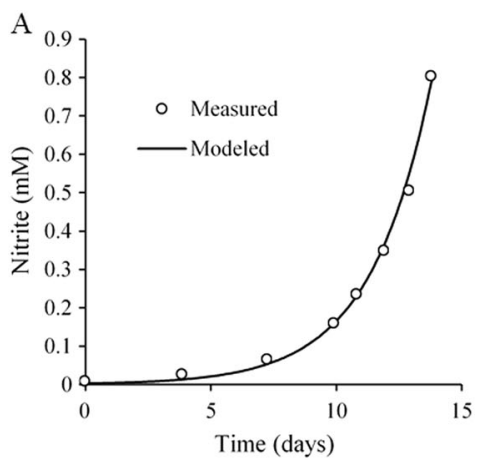

Fig. 1 Representative plots used to determine the maximum specific growth rate $\left(\mu_{\max } ; \mathrm{d}^{-1}\right.$; plot a) half-saturation constant for ammonia $\left(k_{\mathrm{m}, \mathrm{NH} 4} ; \mathrm{mM}\right.$; plot b) and half-saturation constant for oxygen $\left(k_{\mathrm{m}, \mathrm{O} 2}\right.$; $\mathrm{mM}$; plot c) for DW ammonia oxidizing archaea enrichment culture.

\section{Mathematical model}

A one-dimensional biofilm model was used to demonstrate spatial cooperation/competition between AOA, AnAOB, and AOB. The model was implemented using Aquasim software [18], model structure, and diffusion properties from Volcke et al. [19], and typical AOB kinetic parameters from Rittmann and McCarty [20] extrapolated to $30^{\circ} \mathrm{C}$ $\left(\mu_{\max }=1.36 \mathrm{~d}^{-1}, \quad k_{\mathrm{m}, \mathrm{NH} 4}=0.16 \mathrm{mM}, \quad k_{\mathrm{m}, \mathrm{O} 2}=0.016 \mathrm{mM}\right.$, and $b$ (decay) $=0.19 \mathrm{~d}^{-1}$ ). The AOA and AnAOB kinetic parameters determined as described above were used, except the above determined $\mu_{\max }$ was a net growth and therefore, considered $\mu_{\max }-b$ in the model. For the model, $b$ was assumed $0.14 * \mu_{\max }$ (measured) and $\mu_{\max }=\mu_{\max }$

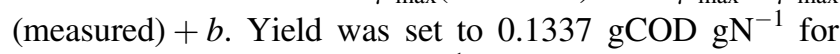

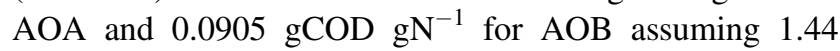

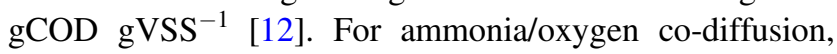
bulk oxygen was fixed to $0.3 \mathrm{mg} / \mathrm{L}$, and for ammonia/ oxygen counter-diffusion oxygen diffused from the biofilm substratum set at $300 \mathrm{mg} / \mathrm{L}$ (approximate air). The models were run for 300 days with a hydraulic retention time of 0.4 $\mathrm{d}$ and influent ammonia of $7.0 \mathrm{mM}$. The complete equations and variables are displayed in Supplementary Information Tables S1 and S2.

\section{Results}

\section{$A O A$ and AnAOB kinetic parameters}

Representative plots used for calculating $\mu_{\max }, k_{\mathrm{m}, \mathrm{NH} 4}$, and $k_{\mathrm{m}, \mathrm{O} 2}$ for the DW AOA enrichment culture are displayed in Fig. 1, and a summary of results for AOA enrichments DW and $\mathrm{AC} 2$ and pure culture N. viennensis are present in Table 1. All parameter curve fittings are present in Supplemental Information Figures S1-S9.

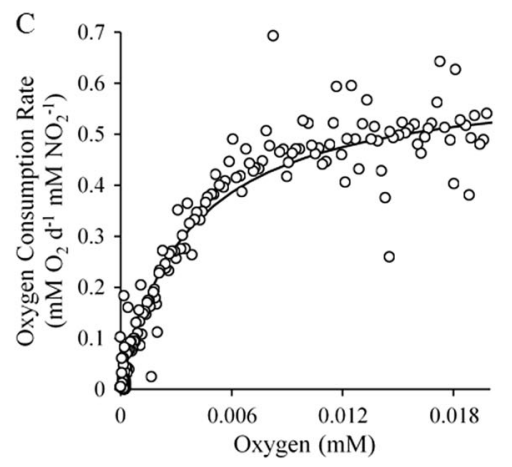

The exponential production of nitrite was used to determine $\mu_{\max }$ in plot A $\left(\mu_{\max }=0.41 \mathrm{~d}^{-1}\right)$. Half-saturation constants were determined using the rate of oxygen consumption in plots $\mathrm{B}$ and $\mathrm{C}\left(k_{\mathrm{m}, \mathrm{NH} 4}=0.77\right.$ $\left.\mu \mathrm{M} ; k_{\mathrm{m}, \mathrm{O} 2}=3.6 \mu \mathrm{M}\right)$

Table 1 Values for $\mu_{\max }, k_{\mathrm{m}, \mathrm{NH} 4}$, and, $k_{\mathrm{m}, \mathrm{O} 2}$ determined for AOA enrichment cultures (DW and AC2) and the pure culture of $N$. viennensis. Each reported value is the average and (standard deviation) of six batch tests for $\mu_{\max }$, and four limitation tests for each $k_{\mathrm{m}, \mathrm{NH} 4}$ and $k_{\mathrm{m}, \mathrm{O} 2}$. Parameter curve fittings are presented in Supplemental Information Figures S1-S9

\begin{tabular}{llll}
\hline AOA & $\mu_{\max }\left(\mathrm{d}^{-1}\right)$ & $k_{\mathrm{m}, \mathrm{NH} 4}(\mu \mathrm{M})$ & $k_{\mathrm{m}, \mathrm{O} 2}(\mu \mathrm{M})$ \\
\hline DW & $0.37(0.03)$ & $0.90(0.24)$ & $2.9(0.5)$ \\
AC2 & $0.34(0.02)$ & $0.61(0.39)$ & $2.9(1.3)$ \\
N. viennensis & $0.23(0.01)$ & $0.81(0.38)$ & $2.8(1.4)$ \\
\hline
\end{tabular}

Representative plots used for calculating $\mu_{\max }$ and $k_{\mathrm{i}, \mathrm{O} 2}$ for the AnAOB enrichment are shown in Fig. 2. Determinations of $k_{\mathrm{m}, \mathrm{NH} 4}$ and $k_{\mathrm{m}, \mathrm{O} 2}$ were done as for AOA (Fig. 1), except activity was determined with pressure change with the OxiTop system. The values for $\mu_{\max }$, ratio of nitrite to ammonia consumed, $k_{\mathrm{i}, \mathrm{O} 2}, k_{\mathrm{m}, \mathrm{NH} 4}$, and, $k_{\mathrm{m}, \mathrm{NO} 2}$ determined for an AnAOB enrichment are present in Table 2. All parameter curve fittings are present in Supplemental Information Figures S10-S14.

\section{AnAOB competition/cooperation with $A O A / A O B$ and mathematical modeling}

For cooperation between AOA and AnAOB to occur there needs to be a balance with oxygen (promotion of AOA/ AOB and inhibition of AnAOB) and ammonia (supplied to both). We address two possible scenarios for this cooperation to occur: microaerophilic conditions, where oxygen is at a level that AOA activity is promoted to the same level as AnAOB is inhibited, and spatial separation, where nitrite produced by $A O A / A O B$ diffuses from aerobic to anoxic environments for AnAOB to consume.

As opposed to ammonia, which promotes growth of $\mathrm{AOA}$ and $\mathrm{AnAOB}$, oxygen inhibits $\mathrm{AnAOB}$ and promotes growth of AOA. Therefore, there is a concentration of 


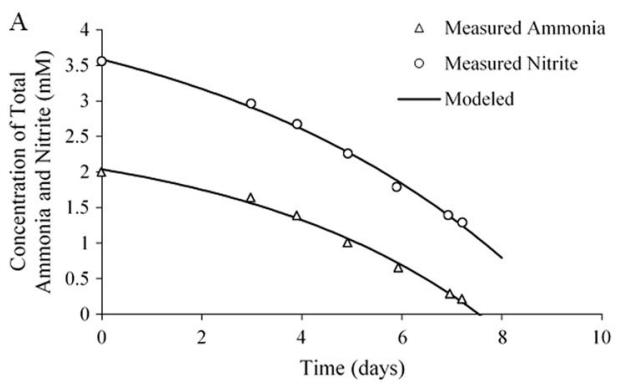

Fig. 2 Representative plots used to determine the maximum specific growth rate $\left(\mu_{\max } ; \mathrm{d}^{-1} ;\right.$ plot $\left.\mathbf{a}\right)$ and half-maximum inhibition concentration of oxygen $\left(k_{\mathrm{i}, \mathrm{O} 2} ; \mu \mathrm{M}\right.$; plot b) for AnAOB. The exponential

Table 2 Values for $\mu_{\max }, \mathrm{NO}_{2} / \mathrm{NH}_{3}, \quad k_{\mathrm{i}, \mathrm{O} 2}, k_{\mathrm{m}, \mathrm{NH} 4}$, and $k_{\mathrm{m}, \mathrm{NO} 2}$ determined for an AnAOB enrichment. Each reported value is the average and (standard deviation) of six batch tests for $\mu_{\max }$ and $\mathrm{NO}_{2} /$ $\mathrm{NH}_{3}$, and four limitation/inhibition tests for each $k_{\mathrm{i}, \mathrm{O} 2}, k_{\mathrm{m}, \mathrm{NH} 4}$, and $k_{\mathrm{m}, \mathrm{NO} 2}$. Parameter curve fittings are present in Supplemental Information Figures S10-S14

\begin{tabular}{lllll}
\hline$\mu_{\max }\left(\mathrm{d}^{-1}\right)$ & $\mathrm{NO}_{2} / \mathrm{NH}_{3}$ & $k_{\mathrm{i}, \mathrm{O} 2}(\mu \mathrm{M})$ & $k_{\mathrm{m}, \mathrm{NH} 4}(\mu \mathrm{M})$ & $k_{\mathrm{m}, \mathrm{NO} 2}(\mu \mathrm{M})$ \\
\hline $0.16(0.04)$ & $1.20(0.05)$ & $0.092(0.080)$ & $132(24)$ & $48(25)$ \\
\hline
\end{tabular}

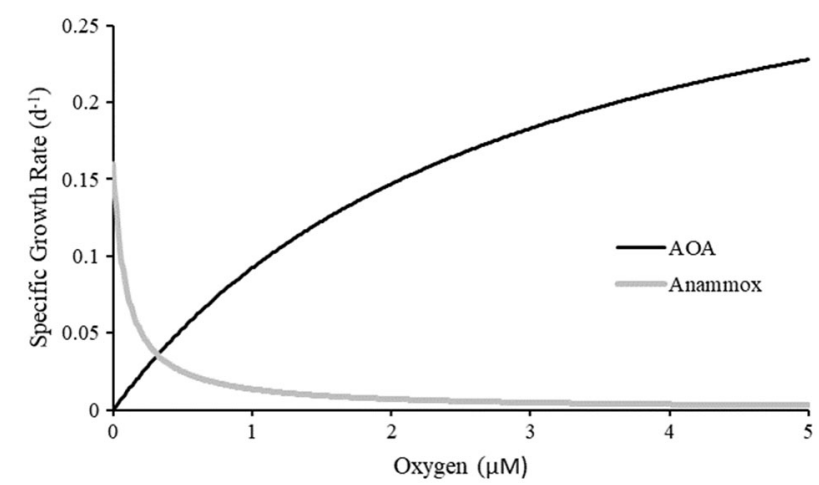

Fig. 3 Average oxygen affinity curve for AOA (using $\mu_{\max }=0.36 \mathrm{~d}^{-1}$ and $k_{\mathrm{m}, \mathrm{O} 2}=2.9 \mu \mathrm{M}$ ) and inhibition curve for AnAOB (using $\mu_{\max }=$ $0.16 \mathrm{~d}^{-1}$ and $\left.k_{\mathrm{i}, \mathrm{O} 2}=0.092 \mu \mathrm{M}\right)$ demonstrating an ideal cooperation point at $0.32 \mu \mathrm{M}$

oxygen that inhibits AnAOB activity to the same level as AOA growth promotion. This is shown in Fig. 3, using the oxygen affinity curve for AOA (generalized to be the average $\mu_{\max }$ and $k_{\mathrm{m}, \mathrm{O} 2}$ of $\mathrm{DW}$ and $\mathrm{AC} 2$ ) and inhibition curve for AnAOB. Because our "activity" was normalized to measured nitrite production or consumption, the point where the curves cross is where the AOA are producing nitrite at the same rate AnAOB are consuming it; $0.32 \mu \mathrm{M}$ or $10 \mu \mathrm{g} / \mathrm{L}$.

Alternatively, spatial distributions could achieve cooperation if nitrite produced by AOA diffuses from aerobic to anoxic environments. To illustrate the separation of aerobic ammonia oxidation and Anammox, Fig. 4 shows modeled

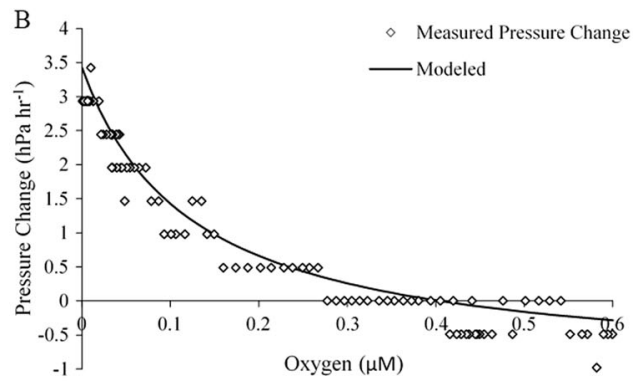

consumption of nitrite was used to determine $\mu_{\max }$ in plot $\mathrm{A}\left(\mu_{\max }=\right.$ $\left.0.15 \mathrm{~d}^{-1}\right)$. Gas production as pressure change was used to determine $k_{\mathrm{i}, \mathrm{O} 2}\left(k_{\mathrm{i}, \mathrm{O} 2}=0.12 \mu \mathrm{M}\right)$

results of a biofilm with oxygen and ammonia supplied from the same side (co-diffusion) and from opposite sides (counter-diffusion).

\section{Discussion}

\section{AOA kinetics}

All three strains of AOA had approximately the same $k_{\mathrm{m}, \mathrm{NH} 4}$ and $k_{\mathrm{m}, \mathrm{O} 2}$. The $k_{\mathrm{m}, \mathrm{NH} 4}$ was also similar to the value previously reported for an AOA enrichment from agricultural soil $\left(k_{\mathrm{m}, \mathrm{NH} 4}=0.69 \pm 0.04 \mu \mathrm{M}\right)$, where the dominant AOA was Candidatus Nirosoarchaeum koreensis, MY1 (99.8\% identical to $\mathrm{AC} 2$ and $81 \%$ similar to DW [15]) [21]. The $k_{\mathrm{m}}$, O2 of the strains from this study $\left(k_{\mathrm{m}, \mathrm{O} 2} \approx 2.9 \mu \mathrm{M}\right)$, however, showed higher affinity for oxygen than that determined for MY1 $\left(k_{\mathrm{m}, \mathrm{O} 2}=10.38 \pm 1.08 \mu \mathrm{M}\right)$. These results further confirm the previous observations that AOA have a higher affinity for ammonia than AOB $\left(k_{\mathrm{m}, \mathrm{NH} 4}\right.$ ranging from $\sim 20$ to $2000 \mu \mathrm{M})$ [8]. The $k_{\mathrm{m}, \mathrm{NH} 4}$ of these AOA is also comparable to the reported affinity of the complete ammonia oxidizing (comammox) bacteria Nitrospira inopinata (0.65 (0.12) $\mu \mathrm{M})$, however in the same study they reported a substantially higher $k_{\mathrm{m}, \mathrm{NH} 4}$ for $N$. viennensis $(5.4(0.6) \mu \mathrm{M})$ than we report here [22]. From a kinetic standpoint comammox and AOA should compete for ammonium and future studies are required to enhance our understanding of their ecological niche differentiation.

The measured $\mu_{\max }$ for the AOA enrichment cultures is similar to that measured by French et al. $\left(\approx 0.38 \mathrm{~d}^{-1}\right)$ [15]. While the measured $\mu_{\max }$ is similar for the two enrichment cultures, the maximum growth rate is markedly slower for $N$. viennensis ( $\approx 33 \%$ lower). A possible reason is that $N$. viennensis has been shown to have an optimal temperature of $35-37^{\circ} \mathrm{C}$ whereas these characterizations were done at $30{ }^{\circ} \mathrm{C}$ [14]. Tourna et al. (2011) also reported that enrichment cultures of $N$. viennensis grew very well, but pure cultures only grew when they added pyruvate [14]. 
Fig. 4 Mathematically modeled comparison of a co-diffusion biofilm (left) and counterdiffusion biofilm (right) removing ammonia via partial nitritation and AnAOB using Aquasim. AOB dominate the codiffusion biofilm, whereas AOA dominate the counter-diffusion biofilm
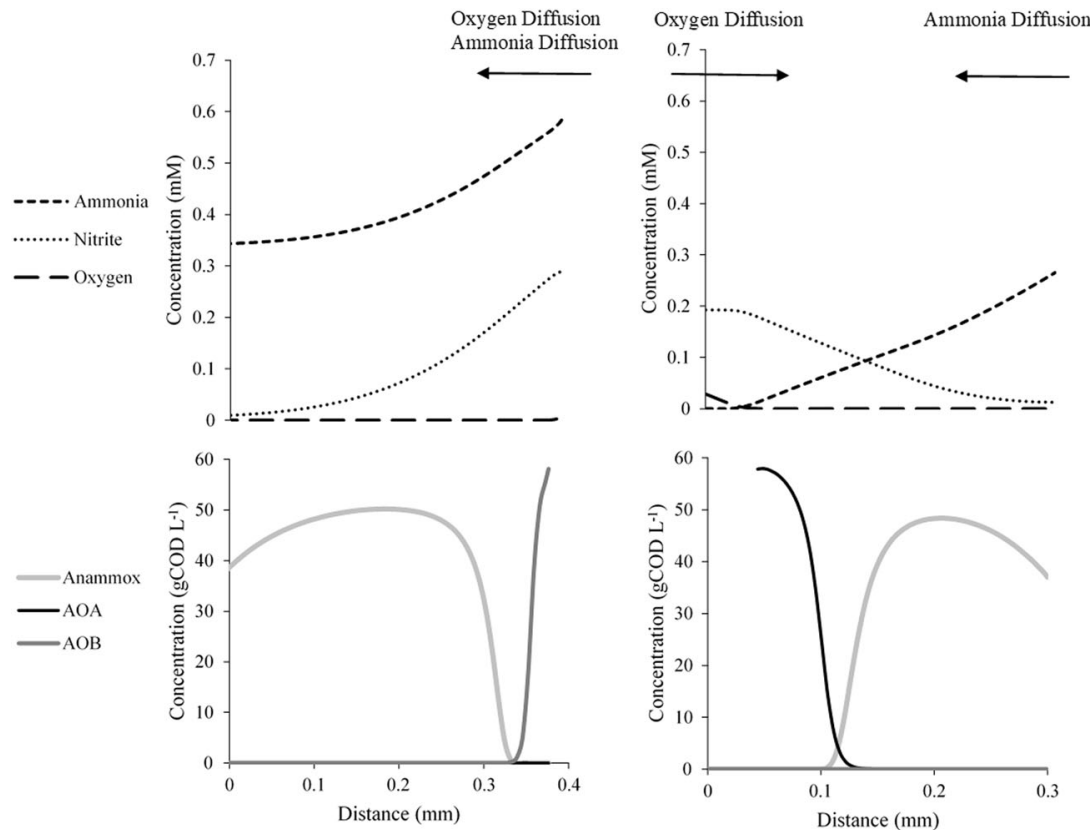

Although, pyruvate was added to the $N$. viennensis culture experiments reported here, it is possible that they are still limited (compared to the two enrichment cultures) due to factors consumed or supplied when growing with other organisms in enrichment culture. Thus, in consideration of high similarity of the other measured parameters for all three AOA, the $\mu_{\max }$ of $N$. viennensis may be closer to that of the DW and AC2 strains characterized in this study.

While affinity characterization can be very useful in determining niche differentiation, it cannot be taken as absolute determinant. As we have shown, there is variability in parameter determination, and other environmental conditions such as temperature, $\mathrm{pH}$, and community factors can be important in apparent kinetic parameters. The extremely high affinity of AOA for ammonia, and a capacity for some to grow at an acidic $\mathrm{pH}$ where ammonium is the major species, has served for speculation that ammonium rather than ammonia is their substrate. Although recent modeling [23] indicates that a charged S-layer typical of most AOA could act to concentrate ammonium near the active site of ammonia oxidation, as yet there is no direct evidence for either species being the substrate.

\section{AnAOB kinetics}

The variability among replicates of the measured parameters for AnAOB was generally higher than for AOA, which is likely due to a combination of: (i) less precise activity measurements (OxiTop pressure sensor for AnAOB verses Unisense oxygen sensor for AOA), (ii) added variability due to clustered growth of AnAOB (despite dispersal of the culture), and (iii) higher degree of community complexity.
Although AnAOB granular biomass was disintegrated, the resulting cells tended to flocculate/cluster again and settle faster, which could have resulted in diffusion limitations in the culture. The measured affinities were similar to some reported values [13], and other studies report much higher affinities for ammonia and nitrite (values for $k_{\mathrm{m}, \mathrm{NH} 4}$ and $k_{\mathrm{m}}$, NO2 that are an order of magnitude lower; down to 5 and 2.5 $\mu \mathrm{M}$, respectively) [24-26]. The likely explanation is niche differentiation associated with affinity differences among AnAOB strains. This enrichment came from a wastewater treatment plant receiving very high concentrations of ammonia and nitrite [16], which likely selected for an Rstrategist population. In contrast, AnAOB that are active in oligotrophic environments, such as found in oxygen minimum zones of the ocean, would be expected to have higher affinities typical of k-strategists. Aerobic nitrite oxidizers show a similar range of $k_{\mathrm{m}, \mathrm{NO} 2}$ values: 9-1400 $\mu \mathrm{M}$ [27]. The $k_{\mathrm{i}, \mathrm{O} 2}$, determined for AnAOB on the other hand, is on the order of the value used by Strous et al. [26] $(313 \mu \mathrm{M})$ and is quite low. Still, it does show some limited tolerance to oxygen suggesting the potential for activity in microaerophilic conditions. The $\mu_{\max }$ reported in literature ranges from $0.0038 \mathrm{~d}^{-1}$ to $0.33 \mathrm{~d}^{-1}$ at $30^{\circ} \mathrm{C}$ [28], and therefore, the value we report is within this range. Similar to affinity, the $\mu_{\text {max }}$ of different strains would be expected to differ based on their environment.

\section{AnAOB competition/cooperation with $A O A / A O B$ and mathematical modeling}

When assessing competition between AnAOB and AOA for ammonia, it is clear that the AOA in this study have a 
higher affinity. The AOA $k_{\mathrm{m}, \mathrm{NH} 4}$ is an order of magnitude lower than the lowest reported $\mathrm{K}_{\mathrm{NH} 4}$ for $\mathrm{AnAOB}\left(k_{\mathrm{m}, \mathrm{NH} 4}=\right.$ $5 \mu \mathrm{M}$ [26]). Thus, in oligotrophic environments with ammonia as the growth limiting substrate, AOA would easily outcompete AnAOB for ammonia. Cooperation between these AOA and AnAOB, on the other hand, depends on both nitrite, from AOA, and ammonia, not consumed by AOA, supplied to AnAOB. Therefore, the oxidation of ammonia by AOA needs to be partial, generating nitrite but not consuming all ammonia. This cooperation can be encouraged by limiting oxygen available to the system (microaerophilic; displayed in Fig. 3) or by spatial separation of the AnAOB and AOA activities (Fig. 4). Under oxygen saturated conditions nitrite oxidizing bacteria (NOB) would outcompete Anammox for nitrite, however this study sets its focus on environments that are oxygen limited-such as oxygen minimum zones in the oceans-and therefore NOB were not integrated into the mathematical models.

Spatial separation can occur in biofilm environments, such as in wastewater treatment where AOB consume oxygen and ammonia at the surface while excess ammonia and nitrite from the AOB diffuse into the lower anoxic areas of the biofilm for AnAOB to consume. However, this depends on ammonia being supplied in excess of oxygen so there is not an over-abundance of nitrite produced. In more oligotrophic environments these biofilms would favor AOA (or $N$. inopinata showing a similarly high affinity) over AOB, but oxygen would need to be significantly restricted to allow ammonia to diffuse to AnAOB. On the other hand, if ammonia was supplied in the anaerobic/anoxic side of a biofilm, AnAOB would have preferential access to ammonia. This leads to a situation where AnAOB are supplied with higher ammonia, shielded from oxygen, and limited by nitrite, and AOA have higher oxygen and limited ammonia, ideal for outcompeting AOB. In a conventional biofilm, AOB/AOA are oxygen limited. This "cross-diffusional" biofilm could form a more natural synergism between AOA and Anammox than through a microaerophilic environment analogous to the cohabitation situation illustrated by Fig. 3 .

From the modeled results, AOB dominate in the codiffusion biofilm, whereas the higher affinity AOA dominate in the counter-diffusion biofilm due to the ammonia limitation created by AnAOB. While cooperation with AOA can be simulated in co-diffusion situations, by limiting ammonia, this restricts the ammonia reaching the anoxic AnAOB layer, and thus the oxygen and ammonia need to be tightly adjusted to show this cooperation.

While counter-diffusion biofilms may not be significant to global nitrogen cycling, analogous situations of counterdiffusion occur within large regions of the marine water column. Taking the Black Sea example reported by Lam et al. 5, oxygen diffuses down from the oxygenated surface waters, while ammonia diffuses up from decay byproducts in the anoxic lower ocean. This leads to higher ammonia and lower oxygen levels in the deeper ocean, more favorable to AnAOB, and lower ammonia and higher oxygen levels in the upper ocean, more favorable to AOA. Similar concentration gradients exist in freshwater environments showing similar population responses [29, 30], and we attribute cooperation in these environments to the counterdiffusion of oxygen and ammonia. The topic of applying Anammox systems to mainstream wastewater treatment is also of interest due to the potential for low energy nitrogen removal; however, achieving low effluent nitrogen concentrations is a challenge [28]. What this analysis suggests is that at low ammonia concentrations, AOA enrichments should be more efficient than AOB, however if AOA and $\mathrm{AnAOB}$ are present in a biofilm, the most ideal scenario would be to provide the oxygen and ammonia counterdiffusionally to allow AnAOB activity (e.g., a membrane biofilm reactor [31]). Common biofilm reactors (granular sludge-based or moving bed biofilm reactors), however, are more difficult to control.

The affinity results presented in this study generally agree with published affinity $k_{\mathrm{m} / \mathrm{i}}$ values for AOA and AnAOB. What has not been established, however, is the impact affinity has on AOA/AnAOB cooperation. Because of the very high affinity of AOA, we propound that it is environment of oxygen/ammonia counter-diffusion that encourage AOA/AnAOB cooperation. To further demonstrate this, growing AOA and AnAOB in a membrane biofilm reactor could be tried or populations in environment where partial nitritation and Anammox co-occure could be surveyed. Furthermore, there is a large diversity of AOA and AnAOB whose kinetics have not been explored and would be invaluable to this work.

Acknowledgments This work was sponsored by the Defense Advanced Research Projects Agency (Contract Number: HR0011-172-0064), the content of the information does not necessarily reflect the position or the policy of the government, and no official endorsement should be inferred. The authors also thank Cristian Picioreanu for assistance in the model development.

\section{Compliance with ethical standards}

Conflict of interest The authors declare that they have no conflict of interest.

Publisher's note: Springer Nature remains neutral with regard to jurisdictional claims in published maps and institutional affiliations.

\section{References}

1. Gao D, Wang X, Liang H, Wei Q, Dou Y, Li L. Anaerobic ammonia oxidizing bacteria: ecological distribution, metabolism, and microbial interactions. Front Environ Sci Eng. 2018;12:1-15. 
2. Oshiki M, Satoh H, Okabe S. Ecology and physiology of anaerobic ammonium oxidizing bacteria. Environ Microbiol. 2016;18:2784-96.

3. Babbin AR, Keil RG, Devol AH, Ward BB. Oxygen control nitrogen loss in the ocean. Science (80-). 2014;344:406-8.

4. Kuypers MMM, Marchant HK, Kartal B. The microbial nitrogencycling network. Nat Rev Microbiol. 2018;16:263-76.

5. Lam P, Jensen MM, Lavik G, McGinnis DF, Muller B, Schubert $\mathrm{CJ}$, et al. Linking crenarchaeal and bacterial nitrification to anammox in the Black Sea. Proc Natl Acad Sci. 2007;104:7104-9.

6. Winkler MKH, Kleerebezem R, Van Loosdrecht MCM. Integration of anammox into the aerobic granular sludge process for main stream wastewater treatment at ambient temperatures. Water Res. 2012;46:136-44.

7. Verhamme DT, Prosser JI, Nicol GW. Ammonia concentration determines differential growth of ammonia-oxidising archaea and bacteria in soil microcosms. ISME J. 2011;5:1067-71.

8. Limpiyakorn T, Fürhacker M, Haberl R, Chodanon T, Srithep P, Sonthiphand P. AmoA-encoding archaea in wastewater treatment plants: a review. Appl Microbiol Biotechnol. 2013;97:1425-39.

9. Leininger S, Urich T, Schloter M, Schwark L, Qi J, Nicol GW, et al. Archaea predominate among ammonia-oxidizing prokaryotes in soils. Nature. 2006;442:806-9.

10. Wuchter C, Abbas B, Coolen MJL, Herfort L, van Bleijswijk J, Timmers $\mathrm{P}$, et al. Archaeal nitrification in the ocean. Proc Natl Acad Sci USA. 2006;103:12317-22.

11. Martens-Habbena W, Berube PM, Urakawa H, de la Torre JR, Stahl DA. Ammonia oxidation kinetics determine niche separation of nitrifying Archaea and Bacteria. Nature. 2009;461:976-9.

12. Konneke M, Schubert DM, Brown PC, Hugler M, Standfest S, Schwander $\mathrm{T}$, et al. Ammonia-oxidizing archaea use the most energy-efficient aerobic pathway for $\mathrm{CO}_{2}$ fixation. Proc Natl Acad Sci USA. 2014;111:8239-44.

13. Zhang L, Narita Y, Gao L, Ali M, Oshiki M, Ishii S, et al. Microbial competition among anammox bacteria in nitrite-limited bioreactors. Water Res. 2017;125:249-58.

14. Tourna M, Stieglmeier M, Spang A, Könneke M, Schintlmeister A, Urich T, et al. Nitrosophaera viennensis, an ammonia oxidizing archaeon from soil. Proc Natl Acad Sci USA. 2011;108:8420-5.

15. French E, Kozlowski JA, Mukherjee M, Bullerjahn G, Bollmann A. Ecophysiological characterization of ammonia-oxidizing archaea and bacteria from freshwater. Appl Environ Microbiol. 2012;78:5773-80.

16. van der Star WRL, Abma WR, Blommers D, Mulder JW, Tokutomi T, Strous M, et al. Startup of reactors for anoxic ammonium oxidation: experiences from the first full-scale anammox reactor in Rotterdam. Water Res. 2007;41:4149-63.
17. AWWA. Standard Methods for the Examination of Water and Wastewater, 20th ed. American Public Health Association; 1999.

18. Reichert P. AQUASIM - a tool for simulation and data analysis of aquatic systems. Water Sci Technol. 1994;30:21-30.

19. Volcke EI, Picioreanu C, De Baets B, van Loosdrecht MC. Effect of granule size on autotrophic nitrogen removal in a granular sludge reactor. Environ Technol. 2010;31:1271-80.

20. Rittmann BE, McCarty PL. Environmental biotechnology: principles and applications. McGraw-Hill; 2001.

21. Jung MY, Park SJ, Min D, Kim JS, Rijpstra WIC, Damste JSS, et al. Enrichment and characterization of an autotrophic ammoniaoxidizing archaeon of mesophilic crenarchaeal group I.1a from an agricultural soil. Appl Environ Microbiol. 2011;77:8635-47.

22. Kits KD, Sedlacek CJ, Lebedeva EV, Han P, Bulaev A, Pjevac P, et al. Kinetic analysis of a complete nitrifier reveals an oligotrophic lifestyle. Nature. 2017;549:269-72.

23. Li PN, Herrmann J, Tolar BB, Poitevin F, Ramdasi R, Bargar JR, et al. Nutrient transport suggests an evolutionary basis for charged archaeal surface layer proteins. ISME J. 2018;12:2389-402.

24. Hao X, Heijnen JJ, Van Loosdrecht MCM. Sensitivity analysis of a biofilm model describing a one-stage completely autotrophic nitrogen removal (CANON) process. Biotechnol Bioeng. 2001;77:266-77.

25. Lotti T, Kleerebezem R, Lubello C, van Loosdrecht MCM. Physiological and kinetic characterization of a suspended cell anammox culture. Water Res. 2014;60:1-14.

26. Strous M, Heijnen JJ, Kuenen JG, Jetten MSM. The sequencing batch reactor as a powerful tool for the study of slowly growing anaerobic ammonium-oxidizing microorganisms. Appl Microbiol Biotechnol. 1998;50:589-96.

27. Nowka B, Daims H, Spieck E. Comparison of oxidation kinetics of nitrite-oxidizing bacteria: Nitrite availability as a key factor in niche differentiation. Appl Environ Microbiol. 2015;81:745-53.

28. Tomaszewski M, Cema G, Ziembińska-Buczyńska A. Influence of temperature and $\mathrm{pH}$ on the anammox process: a review and metaanalysis. Chemosphere. 2017;182:203-14.

29. Schubert CJ, Durisch-kaiser E, Wehrli B, Thamdrup B, Lam P, Kuypers MMM. Anaerobic ammonium oxidation in a tropical freshwater system (Lake Tanganyika). Env Microbiol. 2006;8:1857-63.

30. Wenk CB, Blees J, Zopfi J, Veronesi M, Bourbonnais A, Schubert $\mathrm{CJ}$, et al. Anaerobic ammonium oxidation (anammox) bacteria and sulfide-dependent denitrifiers coexist in the water column of a meromictic south-alpine lake. Limnol Oceanogr. 2013;58:1-12.

31. Nerenberg R. The membrane-biofilm reactor (MBfR) as a counter-diffusional biofilm process. Curr Opin Biotechnol. 2016;38:131-6. 